\title{
Internationalisation at Home: Exploiting the Potential of the Non-nationals' and Expatriates' Community
}

\author{
Andreja Jaklič, Paraskevi Karageorgu
}

\section{A B S T R A C T}

Objective: The paper explores the first-time internationalisation strategy and discusses whether firms could actually begin internationalisation at home without crossing the border by approaching the international expatriates' community in the home city/market.

Research Design \& Methods: The concept of internationalisation at home is studied through the case study method. An example of a public company from the creative industry in the capital city from the Central and Eastern European region is studied.

Findings: The expatriates' community, so far often neglected market segment, has a rising potential in several European cites. The results highlight a positive impact on performance after approaching the expatriates' community. Organisational learning effects result in improved and stabilised sales and strengthened firm-specific advantages.

Implications \& Recommendations: Internationalisation at home is disruptive innovation, especially appropriate for enterprises under high resource constraints. It is fast, cost efficient and has positive externalities. The international expatriates' community in the home city/market offers fast organisational learning and a testing area for enterprises.

Contribution \& Value Added: Internationalisation at home adds to the existing understanding of internationalisation. The findings that firms could begin the organisational learning process of internationalisation before or even without the first foreign entry and proposals for the integrating expatriates' community into the marketing strategy may influence future internationalisation paths.

\begin{tabular}{|c|c|}
\hline $\begin{array}{l}\text { Article type: } \\
\text { Keywords: }\end{array}$ & $\begin{array}{l}\text { research paper } \\
\text { internationalisation at home; international strategy; expatriates' } \\
\text { community; market segmentation; cross-national consumer }\end{array}$ \\
\hline $\begin{array}{l}\text { JEL codes: } \\
\text { Received } 30\end{array}$ & Revised 18 December 2015 \\
\hline
\end{tabular}

\section{Suggested citation:}

Jaklič, A., \& Karageorgu, P. (2015). Internationalisation at Home: Exploiting the Potential of the Nonnationals' and Expatriates' Community. Entrepreneurial Business and Economics Review, 3(4), 49-72. doi: 10.15678/EBER.2015.030404 


\section{INTRODUCTION}

Rising globalisation has stimulated rapid internationalisation of enterprises in the last few decades. The dynamics of internationalisation is particularly high in countries and regions with intensive economic integration processes (such as the enlarging European Union and its single market), in the emerging markets and countries that have gone through an intensive economic, social and political transition process. Not only large multinational enterprises, but also small and medium-sized enterprises (SMEs) are increasingly active in the international arena and the phenomenon has been widely researched in the international business literature over the past three decades (Andersen, 1993; Coviello \& McAuley, 1999; Fillis, 2001; Leonidou \& Katsikeas, 1996; Westhead et al., 2001; Wright et al., 2007). The internationalisation patterns have been changing and diversified. The internationalisation stages or the incremental, multi-stage process of internationalisation - as defined in Uppsala school (Johanson \& Vahlne, 1977, 1990, 2009; Johanson \& Wiedersheim-Paul, 1975) or evolutionary models are often modified and some firms may internationalise rapidly, skipping some or many of the intermediate steps (Madsen \& Servais, 1997; Oviatt \& McDougall, 1994; Turnbull, 1987). A rich stream of the literature on born globals and rapid internationalisation (Madsen \& Servais, 1997; Oviatt \& McDougall, 1994; Turnbull, 1987; Knight \& Cavusgil, 1996; Crick \& Jones, 2000) provides an overview of diverse internationalisation strategies and identify areas that deserve further attention.

While many of the studies evidenced an increased speed of foreign entry, a larger number of markets, and entry to more distant markets already in the early stage or at the beginning of internationalisatiopn (Madsen \& Servais, 1997; Oviatt \& McDougall, 1994; Bell et al., 2004; Dikova et al., 2016), few of them mentioned the option to "start internationalisation at home«. Some very recent studies describing this possibility are related to higher education industry and/or e-learning with empirical evidence limited to cases studies of universities/colleges (Sierra, 2013; Mayoral \& Alvarez, 2014; Yukiko, 2015). Although they stress the importance of targeting a specific market segment for the success of such a strategy (Yukiko, 2015), examples show marketing and internationalisation strategies developed on the country-based market segmentation. There is an idea (similar to tourism industry) to "overcome distance" and attract customers from foreign markets - and not to non-nationals or foreigners (already present or living) in the home country. The existing studies on the internationalisation process also rarely relate the foreign entry strategy with special or adapted marketing segmentation. Business opportunities are normally sought within the selected target markets and market segmentation used in internationalisation strategies is rarely beyond geographical (national) clustering. The algorithms in the cluster analysis and market segmentation predominantly used in marketing agencies, multinational enterprises (also European enterprises - see, for example, El-Kahal in Mercado 2007) can hardly detect a heterogeneous group of consumers. Although the values and lifestyles have been increasingly considered in marketing segmentation (Mitchell, 1983; Beaty et al., 1988; Yankelovich \& Meer, 2006), nationalities remain the key variable for segmentation. The theory and practice have therefore overlooked the rising segment of the non-nationals and expatriates' community. Both the "internationalisation at home" and the "expatriates' community in marketing segmentation " are underexplored topics in 
the international business (IB) and the international marketing literature, and thus the paper aims to fill these gaps.

Our hypothesis is that internationalisation at home, by using the rising potential of the non-nationals and expatriates' community market segment, can become a starting point for internationalisation, before or even without the first foreign entry. It offers the potential for organisational learning, a potential to discover an individual country's/enterprise's/product's potential when starting internationalisation and a marketing segment to be followed in further international growth.

The segment of the non-nationals' and expatriates' community and its potential for implementing the strategy of internationalisation at home was identified in a case study from the entertainment sector, The Art Cinema in the capital of Slovenia, Ljubljana, whereas the cinema product is highly internationalised and therefore reaches the demands of a 'cross-national' consumer. The selected Art Cinema has a strategy of becoming a high quality European cinema, the strategy that has been further developed with the inclusion of Kinodvor in the European Cinemas Network, and therefore represents an excellent example to go beyond Slovene residents and reach also the EU citizens' demand. The European Union (EU) with its single market promotes four freedoms, increased mobility and "Europeanisation«, which enhance the creation of multicultural communities, the introduction of new cultures and the acceptance of new models of lifestyles. Europe, and in particular Central and Eastern European countries (CEEC) that experienced rapid social and economic reforms processes resulting in an increased consumer income and demand for various products which have led to the multinational interest in these countries, thus represents excellent opportunities for exploring and targeting the expatriates' community in marketing segmentation. „Europeanisation (Cernat, 2006) opened a possibility for the CEEC to open their environment for the multicultural community, to create international products and cultures by adopting a welcoming cross-national approach, and can become a valuable competitive advantage for Eastern Europe.

Internationalisation by using the potential of non-nationals' and expatriates' communities in the home market represents a challenge for the creative art industries in the CEEC, a turbulent and low-internationalised sector facing the rising demand. Its major boost for development occurred in the 90s after the fall of communism, when alternative, diverse and multi-layered types of art and culture flooded the Eastern countries. Re-shaping of spaces such as factories into galleries, theatres, etc. has been a normal cultural development. Extremely fast developing post-socialist societies have left behind cultural propaganda and censorship and have made place for cultural liberalism, euphoria trying to resemble the model established by culturally dominant cities, such as London and the US metropolises, combining cultural resources and the exploitation of urban renewal, tourism and image of the economic development, that have become a symbol of freedom and diversity, labels attached to the Western culture values or the so-called developed world. However, the non-nationals as a separate marketing segment is not only relevant for enterprises operating in creative industries (or) in the domestic market but much wider.

Using the mixed-method case study approach, the analysis (i) identifies the weaknesses of the existing market segmentation (ii) characterises the expatriates' community as a new market segment and (iii) presents a case study that demonstrates the gap between the existing and potentially used segmentation and the strategy for including the 
expatriates' community as a new market segment into business (marketing) strategy. The presented strategy highlights the potential for improved business performance and capacity building in culture and creative industries that might serve as a complement to other industries. Internationalisation at home may be seen as disruptive innovation that creates a new market and a value network. The concluding discussion addresses the weaknesses of the existing market segmentation in the European markets and the relevance of the expatriates' community segment for developing firm-specific advantages and locationspecific advantages.

\section{LITERATURE REVIEW}

Most authors view internationalisation as a dynamic and evolutionary process by which firms increase international transactions and commercial engagement with other countries (Beamish, 1990). Often internationalisation is studied on basis of foreign direct investment theories (Anderson \& Gatignon, 1986; Buckley \& Casson, 1993) which explain this phenomenon as the firm's choice of optimal location and structure for each stage of production to minimize transaction costs. Transactions with high risk and high resource commitments may be internalized within the enterprise's organisational structure (Anderson \& Gatignon, 1986; Buckley \& Casson, 1993), leading to an evolutionary process that reflects incremental investments as managers learn about new market environments (Douglas \& Craig, 2011; Newbold et al., 1978). Although high relevance of transaction costs and resources have been identified in several theoretical concepts explaining internationalisation (internalization theory, transaction cost theory, resource based theory), internationalisation at home have not been seen as an option (or stage) in internationalisation strategy, also due to definitions above presented.

\section{Internationalisation at Home}

More recent literature presents the possibility of internationalisation at home. Few existing examples (Sierra, 2013; Mayoral \& Alvarez, 2014; Yukiko, 2015) found in the academic journal data bases (Jstore, EBSCOhost and Proquest) are related to internationalisation in education and concentrate more on using technology and e- services (for example, elearning and e-education) to overcome distance and not the presence of "foreign-consumers" in the domestic market. Internationalisation strategies - also for the first-time internationalisation (and even in the above mentioned studies or projects) often rely on the existing marketing segmentation or cross-country comparative market analysis and rarely demand new marketing segmentation studies.

Although the marketing segmentation analysis is implicitly a part of internationalisation plan(s), there are few contributions that relate these two concepts or tools in marketing segmentation that would be especially appropriate for the first time internationalisation. The starting point and a "classical" recipe for making a strategic plan for foreign entry in IB textbooks is normally a country analysis (see for example Cavusgil et al., 2008).

However, as suggested by Agarwal (2003), a country analysis to discover the segment for international marketing using the gross national product per capita and factors such as economy, politics and health are highly limiting. By using Hassan's and Katsanis' research from 1991, Agarwal identified the weaknesses of such a model among country-specific marco-variables; the lack of consumer-behaviour variables; the assumed homogeneity of 
consumers within the country segments; and the overlooking of the existence of homogenous segments that exist across national boundaries (Agrawal, 2003). All these three weaknesses are extremely important for our segmentation proposal, and in many terms the paper is an attempt to overcome them.

Other suggestions for entering new markets include the Kale and Sudharshan twostep approach by Kale and Sudharshan (1987) and Kreutzer (1988), which includes the choice of the potential countries and the implementation of the in-country segmentation, the various in-country segments are compared across countries and the ones similar in the country are consolidated into strategically equivalent global segments.

However, we propose the extension of this idea. At least in the European context these two steps can be combined into one, by using the expatriates' community within a country and combine the in-country segmentation with the choice of potential countries. Ideas how important "foreigners" or non-nationals can be for outward internationalisation are rarely presented (Maister, 2015) and the segment of the expatriates' community neglected in internationalisation strategies.

The advantages of internationalisation at home are multi-fold and may result in (i) cost efficiency and (ii) higher dynamics (speed) of internationalisation process. As the segment is at the direct reach of an enterprise, this may lower the cost of distribution and communication, prevent high transaction costs (that are present with foreign entry). Firms may become familiar with foreign consumer behaviours, attitudes and their needs without moving beyond their border, and they can also assess the attractiveness of their brands among foreign consumers. Experience and adaptation may result in faster learning and knowledge that can be used for further international growth and market development or targeting similar consumers in other countries or globally (as proposed by Hassan \& Katsanis, 1991).

\section{Marketing Segmentation Analysis and the Mobility of Consumers}

The principle of segmentation in marketing, introduced by Wendell Smith (1956/1995) as an alternative to the product differentiation strategy, has been largely accepted by marketing practitioners over the past years and follows the rule to find and understand a marketing segment and to communicate with it with the content and style most likely to appeal to it (Narin \& Berthon, 2003). Different variables have been used to determine a marketing segment - such as shared membership, age, gender, income, geography and buyer behaviour.

Narin and Berthon proved the supremacy of the personality variable when it comes to consumer behaviour. These authors have followed the development of these phenomena since the end of World War II and its 'transformation' into categories, such as "lifestyle", "psychographic", "attitudes and activities" and "values" (Narin \& Berthon, 2003). A specific part of their research is the argument of the Advertising Research Foundation (ARF) which states that people tend to be consistent in coping with their environment. This argument is important also for this paper. If individuals react fairly consistently in a variety of environmental situations, these generalised patterns of response or modes of coping with the world can be called personality that is transferrable. In fact, the pattern of people moving from one country to another highly influences their consumer behaviour. On the one hand, they carry the 'personality traits' of their environment; on the other hand, they adopt new consumer behaviours in coping with their new environment. In both 
cases, they represent new consumers - more internationalised and mobile - who are influenced by these patterns. The potential of this group is based on a regular flow as a consistent number of people moves into another country every year.

These patterns need to be analysed and a potential for marketing segment further evaluated. They are relevant for a number of sectors: from real estate agencies to food chains and entertainment. For example, we have already witnessed how short-term mobility programmes in Europe have changed the real estate renting practices where renting legally an apartment for less than a year seemed impossible before, while it is fully normal now. The online services for expatriates (such as InterNations or expatriates.com) further demonstrate the need.

Market segmentation with the cluster principle has been widely used in marketing. Values and lifestyles have been increasingly considered in marketing segmentation (for example, VALS developed by Mitchell, 1983; Beaty et al., 1988; Yankelovich \& Meer, 2006), however nationalities (and other traditional demographic traits) keep the importance in the segmentation analysis. The concept of Euro clusters, for example, was developed according to similar economic, demographic and/or lifestyle characteristics (Vander Merwe and l'Huillier in Mercado 2007). However, the variation of this cluster segmentation is basically regional segmentation that is losing relevance in the EU. Cultural integration in Europe is speeding up, and clusters combining among personal characteristics, industries and interests shall be a new field of marketing and product concentration, or, in other words, segmentation according to lifestyles, interest, tastes, attitudes and values, as El-Kahal suggested already in 1998 (El-Kahal in Mercado, 2007). Segmentation working closely with variables, such as age, socio-economic background, mobility of consumers, and profiles could revel latent segments and bring into a new kind of 'inclusive' marketing. Researchers can examine the relation of these variables to the consumption of specific products even within one country. Lifestyle and values of the "expatriates' community" may be more heterogeneous (than traditionally defined clusters), but the combination of variables can reveal the way in which such (mobile) consumers react to product/service offerings, advertising, packaging, pricing, personal selling, and retailing. An effective marketer should be aware of this influence and incorporate it when developing marketing strategy for nonnationals and when planning products (Beaty et al., 1988).

The proposed new approach corresponds with the definition given by Agarwal (2003), that "the success of any segmentation approach depends on the ability to find segments in which within-group difference in individual demand functions are smaller than between-group demand functions". Our proposal follows the idea that "demand functions themselves should be the theoretical basis for segment definition" (Dikcson \& Ginter in Agrawal, 2003).

Similarly, as firms and marketing specialists try to explore the global market and try to identify the global market segment(s) and reach them with products and marketing programs that meet common needs of these consumers, segmentation could be done as the initial steps in analysing the non-nationals' community consumer behaviour within the home market first, and then identify the specific needs of such groups and meet them.

Another theoretical basis useful for this approach is the consumer-product based relations developed by Hofstede, Steenkamp and Wedel in 1999. International segmenta- 
tion studies based on macro-level geographic, political, economic and cultural data provide only insights into which groups of countries can be potentially targeted, but no information about which groups of consumers within those countries will respond to the marketing efforts. Using consumers, instead of countries, as the basis for identifying international segments, would therefore increase the effectiveness of a marketing strategy and internationalisation.

This concept is close to the one of the 'global consumer' - a transnational consumer with similar characteristics and aspirations (Walters \& Toyne, 1989; Yavas, Berhage, \& Green, 1992). Only that this consumer is to be found in a specifically targeted transnational group within one country. The same concept that is used to reach a group of consumers with a similar profile across countries is used in the internationalisation not outside, but inside, in the home market. As in the cross-national segmentation consumers in different countries are grouped based on similarities in their needs, ignoring the country borders (Kamakura, Hofstede \& Yavas in Hofstede, Wedel \& Steenkamp, 2002), our case keeps the awareness of the borders and identifies the cross-national segmentation differences within a country. This proposal also surpasses the limitations of the model of spatial segmentation which presents the dependence of the identification of a cluster on the geographical space similarities and therefore an inevitable presumption of homogeneity (Hofstede, Wedel \& Steenkamp, 2002). The spatial segmentation in terms of a cross-national consumer (Steenkamp \& Baumgartner, 1998) behavioural similarities, such as the similar physical and psychological landscape represents only a characteristic for starting the internationalisation at home marketing strategy.

\section{The Potential of the Non-Nationals' and Expatriates' Community Market Segment}

Free mobility has influenced the creation of non-nationals' and expatriates' communities within countries all over Europe. This phenomenon is developing in terms never seen or experienced before. Exchanges for students, teachers, professors and workers, the facilitated labour mobility across Europe etc. has made out of every big to medium city a place with the existing international communities. This community is formed even by local residents who were abroad and once they are back they feel that they belong to an 'international' area of cultural exchange. The fact that multicultural collaboration is boosting creativity, innovation and progress is widely recognized in business literature, recently also by Alison Cook and Christy Glass who prove that firms with a traditional CEO but a diverse board are most successful at innovating (Cook \& Christy, 2015). The possibility of the local management to have this experience is therefore of extreme importance. Relations with international audience/customers are an important element for developing international marketing and different segmentation. Establishing the relations with the expatriates' community, in this case a specific segment being the non-nationals' community within the home market, can thus be seen as a part of market research and development. This market segment and internationalisation "at home" may enhance firm growth and the likelihood of survival, especially when domestic markets are small, mature or highly competitive (Coviello \& Munro, 1995).

While the personality variables are unstable and predisposed to changes, the free mobility and movement provide exactly the opposite pattern in consumption behaviour. On the first look, people with different cultures are bound in their consumer behaviour and 
personality by one characteristic, i.e. 'foreigner' that easily gets into the spiral of consuming two types of products:

1. Products that are familiar, such as bank products, mobile operators, food chains, etc. (it is more likely that a consumer will open a bank account in the same bank abroad that he uses at home or an internationally established bank, therefore, cross-national loyalty is a possible new segment of a brand's marketing). Nairn and Berthon have conducted a number of studies that have shown that the consumer's mind is not a blank sheet awaiting advertising but already contains unconscious memories of product purchasing and usage. Therefore, the processing of advertising messages feeds back to the experience which in our marketing segment has a key role (Nairn \& Berthon, 2003).

2. Products that help integration (food, clothes, music, entertainment, local popular services) - therefore, the integration development can become a new segment of brand strategy to attract new customers. Thus, promotion of integration may contribute to corporate social responsibility (CSR) as well, as enterprises are a part of the integrative and anti-discrimination socio-economic process.

These two different types of products represent a combination between standardisation and adaptation product strategy. In this case, the beneficial use of certain product increases contributes to the consumers' value and in this way creates an added value, nonexistent before. That increases competitiveness as well, as "values underlie a large and important part of human cognition and are among the most central determinants of consumer behavior" (Steenkamp, Hofstede \& Wedel, 1999).

The commonality of the English language is of crucial importance for this market segmentation. Becoming the language adopted by international communities to communicate between each other is the method of finding their way in the new environment therefore presents, books, menus introducing information in English are becoming prioritising products/services.

The European youth consumption is an example that can be used in order to explore the connection between the two already explained approaches (the socio economic category - age and identifying personal characteristics of the youth). Multinational companies have already tried to explore this segment of marketing strategies in terms of music tastes, food and drink habits, fashion, and sports (for example Nike). Mercado gives an example of successful marketing of the Swedish company IKEA which is targeting at young consumers all over Europe, combining the European tradition and following their lifestyle and quickly changeable tastes. However, even IKEA's has marginalised and to some extent even neglected the non-nationals in European countries. Despite being an international brand, it does little to attract the non-nationals to its stores abroad (if an Italian is in Austria and wants to check the availability of the product range, dimensions, order a product, arrange its delivery and so on, he can do so only in German and cannot check the local supply in English on the web page), which confirms the unexploited potential of the expatriates' community consumers and market development. Internationalisation is predominantly viewed in spatial/geographical terms.

The potential of this market segment can be quickly revealed by migration statistics, showing a regular and increasing flow of people who move into another country every year (Eurostat, 2014a, 2014b): 
- The EU level reveals a significant segment of such customers; in the year 2013 the Member States issued around 2.36 million first residence permits to third country nationals. According to Eurostat, this represents a $12 \%$ increase of permits compared to the previous year when around 260 thousand more permits were issued (Eurostat 2014a).

- On 1 January 2013 in absolute terms, the largest numbers of non-nationals living in the EU were found in Germany (7.7 million people), Spain (5.1 million), the United Kingdom (4.9 million), Italy (4.4 million) and France (4.1 million). Non-nationals in these five EU Member States in total represented $77 \%$ of the number of non-nationals living in the EU-27, while the same five Member States had a $63 \%$ share of the EU's population. In relative terms, the highest share of non-nationals in the EU-27 Member States was in Luxembourg (44\% of the total population). A high proportion of non-nationals ( $10 \%$ or more of the resident population) was also observed in Cyprus, Latvia, Estonia, Ireland, Austria, Belgium and Spain. In total, in the EU in 2013, the EU-27 foreign population (people residing in an EU-27 Member State with citizenship of a non-member country) was 20.4 million, representing $4.1 \%$ of the EU-27 population. In addition, there were 13.7 million people living in an EU-27 Member State on 1 January 2013 with the citizenship of another EU-27 Member State (Eurostat, 2014b), which shows the considerable size and growth of this segment.

- Similar is the share in the country of our case study, i.e. in Slovenia. In 2014 there were 94840 foreign residents with valid permission for a stay in Slovenia (Ministrstvo za zunanje zadeve Republike Slovenije/Ministry of Foreign Affairs 2014a), and in the same year 11342 people had such a permission issued (Ministrstvo za zunanje zadeve Republike Slovenije/Ministry of Foreign Affairs 2014b). Considering the total population of Slovenia, which counts to 2045431 people, means that the people with the valid permission represent $4.64 \%$ of population.

If we look at some short mobility data, we can see that the University of Ljubljana is at the top 10 destinations for Erasmus exchange, receiving 1072 exchange students for 2012-2013. Since the launch of the programme more than 3 million students have benefited from student mobility. For the years 2012-2013 there were 268143 students participating. Spain sent out the most Erasmus students for both studies and placements (39 249), followed by France (35 311) and Germany (34 891). Spain was also the most popular destination country with 40202 incoming students, followed by Germany (30 368) and France (29 293). The United Kingdom hosted almost twice as many students (27 182) as it sent abroad (14 572) (European Commission 2014b).

Although significant in terms of volume, the segment of the non-nationals' and expatriates' community on home market is not easy to define as it is a status 'in between'. The individuals making part of it are not locals, but they are also not tourists. They are sorted into »different clusters in traditional segmentation «, but do not fit in well, and the existing communication and distribution channels are often not adapted to their needs. They are familiar with the culture and habits of the host country; however, their process of integration is slow and a need for learning and exploring local products enormous. This is part of their inclusion in the new society, the environment they are in and a process of claiming the new place they have been found in.

However, in the cluster segmentation analysis and development of markets, internationalisation at home has been overlooked, as it cannot be identified with the existing set 
of algorithms and variables. Therefore, new variables and tools need to be used in order to identify latent segments and evaluate the potential of this new kind of segmentation. The potential of the non-nationals' or expatriates' community marketing, or starting the internationalisation at home is a highly ignored concept and often mistaken as 'spreading an activity abroad' or in the home country terms as tourism. Based on mobility statistics, in-depth interviews and exploration of customers (presented within the case study in the next section), we argue that "the non-nationals' community within the home market" is an underexploited segment, not-yet identified segmentation procedures and as such marginalised in both marketing and internationalisation strategies.

Internationalisation starting at home tackles the non-nationals within the existing local market - something so far ignored by many businesses - being private, or local/ public. It may involve tourists as well, however, it shall not become a tourist attraction per se. From a practical, managerial point of view, there are several approaches towards the international communities to be adopted:

1. Non-nationals at home as an exclusive market to be targeted.

2. Non-nationals' and Expatriates' Community at home as a testing space - exploring the potential of a product for later entering foreign markets (exploring the market responsiveness, and segmentation strategy before going international or global).

3. Non-nationals and Expatriates' Community as a target market in foreign countries or as a global segment existing in several markets/cities.

The potential advantages of addressing the non-nationals and expatriates on the home market are numerous and they all contribute to the long-term development of an entity/enterprise and the society and the location. Thus, the effects may be seen in both firms-specific advantages and in location-specific advantages (as stated in Dunning's eclectic paradigm (Dunning, 1988) or understood also as supportive and complementary activities in Porter's diamond):

- The segment of non-nationals and expatriates offers the potential for starting internationalisation at home, representing a clear indicator for possible international success of a product. The segment is manageable as it is homogenous in terms of essential marketing elements, the classic 4 Ps (product, price, place, promotion) and to a large extent even additional 3 Ps -Physical evidence, Process and People, to which the response of the non-nationals or expatriates' community could be especially sensitive. As this segment is characterised by highly unified tastes, due to the profile they share - this segment unilaterally clashes with a new type of culture, desire for integration, difficult comprehension of local customs, and therefore shared ways of thinking. Any product that gravitates around such ideas (integration, domicile emotions, nostalgia, internationalisation, products that go beyond the national identity), therefore unifies this type of a market.

- Enterprise /firm-specific advantages may reveal in different ways. The "new" segment "non-nationals in the domestic market" means an increased number of customers, increased sales, more stable sales revenues, lower marketing (communication) costs (compared to addressing other nationalities outside the domestic market due to no transportation costs), increased innovation and intangible assets, spill over to other business functions, possibility for testing space for further internationalisation. "Inter- 
nationalisation at home" may exacerbate enterprises' liabilities of smallness, for example by introducing additional complexity (Lee et al., 2012), by struggling to secure the financial resources required for successful growth, by exhibiting the shortage of managers with international experience (Coviello \& Martin, 1999), or by incurring negative country-of-origin associations (Svetličič, Jaklič \& Burger, 2007).

- Social value added to national residents by being included into the 'Europeanisation' or 'Globalisation' of the world, communicating in different languages, personal development through the contact network development between cultures, enhancing knowledge spill over and enable intercultural communication that may decrease the psychic distance.

- Social value added to the non-nationals and expatriates by facilitated integration into a foreign environment, accessibility of this new environment, possibility to 'claim it' as personal space.

- A country's or region's image, popularity - the image of a whole city (region, country) improves due to its openness, exchange of ideas and created co-operation. Could be used for tourism advantage, as something specific, unique, interesting, and complement or support other industries. Tourist experience that will actually make people less tourists and more 'travellers seeking local life', and therefore will easily 'fit-in'.

- CEE countries are relatively less popular destinations for tourists and expatriates and this strategy gives them a chance to form a marketing strategy and competitive advantage for this group, and the business environment. Slovenia, for example, has been doing so over the last two years: its tourist image relies on ecology, green space, environment-friendly activities and internationally attractive cultural events (cycling, climbing, film/music festivals and so on) and in this way attracts certain kind of people not only for travelling, but also for the exchange and other long-term residential decisions of the EU citizens, provided with the possibility to choose a country to spend a certain amount of time in. These activities contribute to the formation of unique location advantages which achieve spill-over effect, in the attraction of certain people, businesses and initiatives.

\section{MATERIAL AND METHODS}

The strategies of the rapid and "unusual " internationalisation pattern have been mostly analysed through case studies which are compared to firm-level studies more able to capture complex and multidimensional processes. To analyse and describe the proposed internationalisation strategy, the explanatory case study methodology was followed, using document analysis, focus groups, in-depth semi-structured interviews and participant observation as the main methods for data collection. The multi-method or mixed methods case study approach (Hurmerinta \& Nummela, 2011, p. 211) was used with data collection and analysis, since the topic is complex, combines concepts from different disciplines (international business, marketing, business environment, economic policies) and different types of data. It requires a variety of methods in order to mirror the phenomenon and add to the existing knowledge base. The paper describes a new segment that has not been described in the literature or among the existing internationalisation strategies.

The research strategy is based on a larger number of enterprises (case studies) and their first-time internationalisation strategies which have been studied for years within 
the IB course and one of them was selected for a deeper study due to a different starting point. The strategy for internationalisation at home and the segment of non-nationals and its potential was identified in the comprehensive case study of the Art Cinema (Kinodvor) from Ljubljana (the capital of Slovenia). The selected case study is based on explorative research (in-depth interviews, the enterprise's Facebook profile research, management and staff surveys, customer surveys, in-depth semi-structured interviews and participant observation methodology). Data gathered between the years 2012 - 2015 provide a rich data set, available for further qualitative and quantitative analysis. The mixed method case study with an "aggregated strategy" seemed also appropriate as the case has more than one purpose: 1 . Studying possible first-time internationalisation strategies and 2. examining marketing segmentation and methods that are usable for the first-time internationalisation strategy. As the enterprise faced very limited resources and no extra capacities for internationalisation, more detailed customer segmentation was carried. Within this process, the segment of the non-national i.e. international consumers was identified and its potential explored further via different methods and data analysis (data from interviews, Facebook profile analysis, personal observation, etc. were used as strategic analytical tools). This paper presents only a small portion of the data and analyses collected within the case study.

For market positioning and segmentation we use Rentschler's product and organisational marketing model (Rentschler, 2004) and Human Factors International Quadrant (HFIQ) (Goethe-Institut e.V. \& Leuphana University, 2015). These two tools by complementing each other allow to measure the added value and sustainable development potential of an institution/business. While the Rentschler's model provides a theoretical framework for placing the marketing realities and opportunities, the HFIQ allows to directly measure and understand the audience segmentation/prioritisation applied by the CEOs and shows if it corresponds to the actual situation. With the help of these two strategic marketing and management instruments, the case study explores the potential of the market development of the international audience of the Art Cinema in Ljubljana.

The case study presents both (i) a gap between the existing and the potential market segmentation and (ii) a strategy of starting internationalisation at home, which could be implemented by other entities as well (or be applied to other specific age and social groups).

The case study of the Art Cinema named "Kinodvor" from Ljubljana (founded by the Municipality of Ljubljana, the capital of Slovenia) was chosen as its marketing strategy is highly oriented towards the audience development and the product popularisation and as it already enjoys popularity and high success within the local community. Its main product - film, has high attraction and frequency that did not fall even during the financial crisis, though cinema industry in general faces huge challenges in keeping growth due to the Internet technology and development of substitutes (Netflix, Voyo, etc). Next, the institution is situated in proximity to an area popular among international visitors (most famous alternative culture gathering place, most famous alternative hostel in Slovenia etc.), so the impact on the (micro and macro) location and the effect complementary to other activities can be explored. 


\section{CASE STUDY: KINODVOR ART CINEMA}

\section{Kinodvor in Focus}

First, we present the cinema's realities and marketing strategies and then show how the specific strategy for the non-nationals or international community segment fits into its further development. During the studied period from 2012 to 2015, Kinodvor succeeded not only to keep, but also to enlarge its audience in spite of the recession on the local market (Figure 1). The majority of other cinemas, (basically all competitive cinemas in Ljubljana) experienced a drop of visitors and sales. Figure 1 illustrates the growth of visitors and the rising share of international visitors.

Kinodvor marketing is oriented at the domestic market and the segmentation is based on the age differentiation. Variables such as age and education are the most important variables used for customer differentiation in market segmentation and the marketing strategy of Kinodvor. In practice, neither age nor education has not been segmented in detail, but serve only for the broad definition of the key groups (e.g. kids and adults/ or professional/movie experts and others) to be targeted and to look for synergies among them. Loyalty programs and social networks management have not (yet) been adapted to the recognised market segmentation.

The Art Cinema places a great emphasis on developing a specific program for a specific target audience. It has a special program for children and young people - which enjoys extremely high frequency. The enterprise has introduced a special entrance fee for parents with new-borns and retired people, reassuring strong social engagement (Kinodvor Strategy 2011-2015). The main approach of the Cinema is to embrace all generations and provide social values for all of them, however a marketing strategy (at least some elements of the marketing strategy) approach has been explicitly developed separately to almost all age groups. Children and youth are considered together. The identified gap is within the group of young audience, and especially students who constitute the majority of the audience aged 18-25 do not have special mentioning neither in the strategy, nor in the yearly reports and there is no accurate data about their visit frequency. However, Kinodvor realises that an important segment of its audience has been neglected, and considers the inclusion of the youth in its future strategies, as for example it is the film festival Kintotrip, to be held for the first time in 2016. An initiative in this direction will be a Youth Film Festival to be held in 2016. The children, however, are tackled specifically. Having in mind that Kinodvor is a public institution with only one screening hall, it still manages to offer a big range of film offerings for different audiences. However, the big potential of the programming it offers creates a rising demand, and tackling the non-nationals and expatriates further is a great stimulus for the cinema's expansion. 


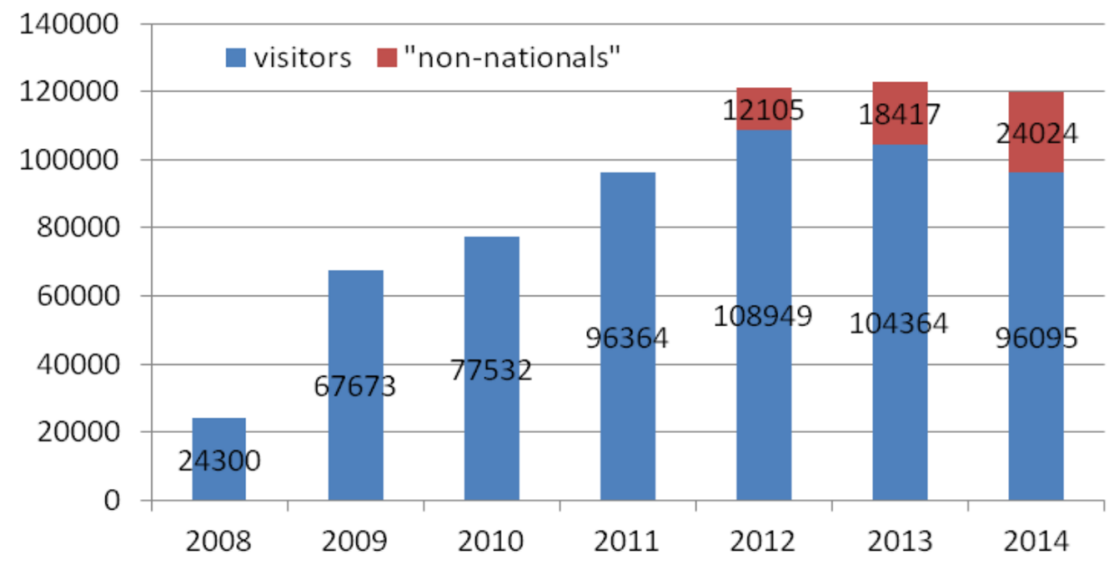

Figure 1. The annual number of visitors in Kinodvor in the years 2008-2014 Source: own estimation based on Kinodvor data.

\section{Mapping the Kinodvor Audience}

In order to define the cluster positioning of Kinodvor, the Human Factors International Quadrant, developed by Goethe-Institut and Leuphana University, has been used. This method is useful in order to map Kinodvor's audiences. The Quadrant represents a twoby-two matrix that maps the Frequency of Activity across the Importance of Activity, drawing on the vision and mission of the organisation. The following matrix represents the activities/audiences according to Kinodvor. The staff was given an empty quadrant and had the task to fill in with the following marketing segment groups:

- Children, youth;

- Middle age;

- Elderly;

- Youth (Slovene residents);

- Youth (International Community);

- International Community (Expatriates', non-nationals).

As described above, in the existing Kinodvor's segmentation, age is the primary variable used in determining its marketing strategy. Attention has also been given to the other clusters that are of interest of our research, such as nationality (divided to the youth and the international community (non-nationals) in general, as the international (non-national) youth access is facilitated through student network organisations and social networks).

The following diagram (Figure 2) shows that Kinodvor's management has a unilateral view regarding age and nationality division, and does not divide either their importance or their frequency. For this reason, we observe that the age segmentation has high frequency and high importance, while the nationality segment of the market is to a larger extent ignored by the marketing strategy. The next figure (Figure 3), however, created by the authors, and based on the segmentation of visitors (based on the participation and the surveys) argues, that even if not existing in the marketing strategy, there is an impact of this segment and therefore, their presence must be recognised. 


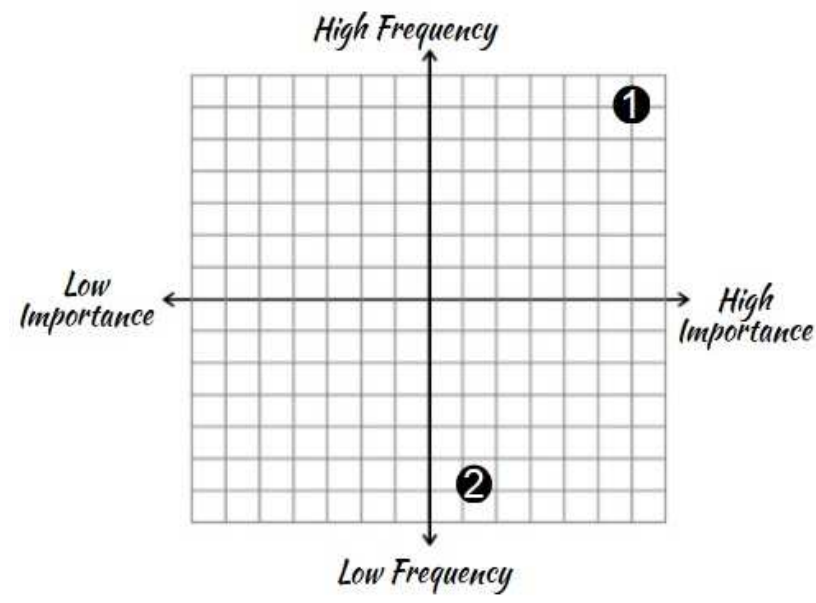

Group 1: Children and Youth, Middle age; Elderly

Group 2: Youth (Slovene residents); Youth (International Community); International Community

Figure 2. Strategic positioning, representing Kinodvor's cluster segmentation Source: own study.

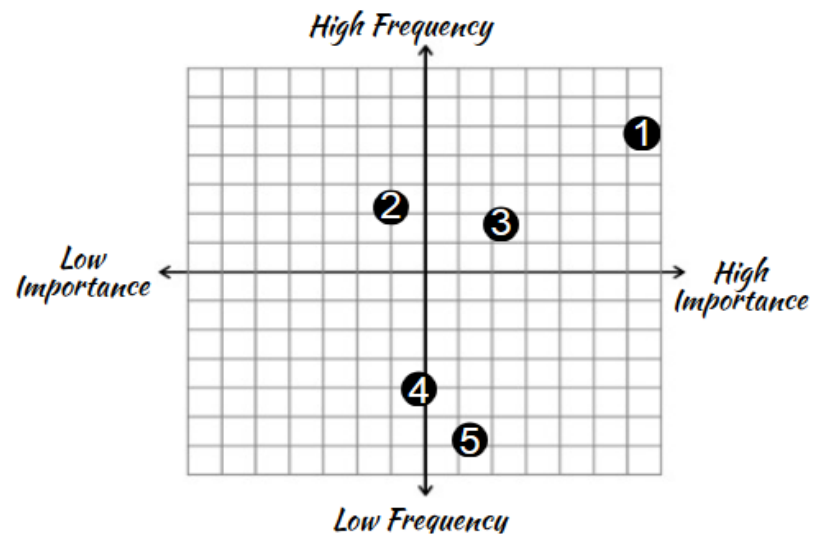

1 - Children

2- Youth (Slovene residents)

3 - Middle age; Elderly

4 - Youth (International

Community)

5 - International Community

Figure 3. Detailed audience cluster segmentation of Kinodvor Source: own study.

Estimations based on the participation observation and the survey showed that the international (non-nationals) community represents a significant market segment. The variation of the non-nationals is relatively high and they may range from 0 to $50 \%$ share (depending also on language of cinematograph films), and is estimated to be between 15 and $20 \%$ of the total audience. This (already present though) potential audience recently has no place in Kinodovor's strategy. However, it matches the vision and the mission of this art institution whose commitment is that at least $25 \%$ of its film programme must consist of European, non-Slovene movies (Kinodvor Strategy 2011-2015). This immediately opens the potential for many international residents in Ljubljana to visit Kinodvor. Therefore, it corresponds with the first managerial approach: "to treat the expatriates' community as a market to be targeted". On the other hand, as Kinodvor serves as a platform for quality films screening especially Slovene productions, expatriates' communities and their 
engagement with the institutions can bring the needed feedback for a certain film. Here, there is a further opportunity for collaboration between Kinodvor and Slovene films' distributors. This involves further cooperation for the estimation of the performance of Slovene films for festival nomination choices and even further investment decisions and corresponding with the second managerial option, to use "Expatriates' Community as a testing space - exploring the potential of a product for later entering foreign markets".

The two matrix quadrants (Figure 2 and Figure 3 ) show the major differences that Kinodvor experiences when it comes to marketing strategy and audience segmentation. The first quadrant represents the CEOs and the marketing management segmentation - we see strictly demographic segmentation, which is highly general and puts together diverse audience segments. This visualisation contradicts the statement of prioritisation. The second quadrant placed a more detailed audience segmentation which more accurately reflects the Kinodvor realities based on the participation and observation research conducted in 2013-2015. Thus, a clear mismatch of priorities and marketing segmentation occurs. It becomes obvious that without further segmentation and research into the potential exploitation of neglected clusters and spillover effect opportunities coming from them, no clear vision of the existing and future audiences can be adopted. Figure 3 presents the possible positioning in cluster segmentation of the international community (non-nationals) segment. With the help of the Rentschler's model and the comparison between the two quadrants, we conclude that internationalisation starting at home is highly ignored, but hides a lot of potential. The biggest missed opportunity is concentration on the local audience development that excludes non-nationals, without realising that the second brings immense value added to the first and vice versa.

Kinodvor, however, realized the missed opportunities due to a scarce differentiation of marketing segmentation. For this reason, the Art Cinema has developed a new tool an electronic data base that allows segmentation according to different categories, such as personal interest, professional orientation, and foreign language, which is the most relevant category for tackling the expatriates' community market. However, although the existing tools target non-nationals, they are still not seen as a market segment that needs to be tackled separately (as we can see from the Figure 2).

\section{Proposals for Integrating and Using the Expatriates' Community into Kinodvor's Marketing strategy}

Next, we propose steps how to approach foreigners and the expatriates' community segment. In order to analyse the potential of the international audiences at home systematically, we use the diagram of tripartite audience (Figure 4), i.e. product and organisational marketing model developed by Ruth Rentschler (Rentschler, 2004). Rentschler developed this model to analyse the changing marketing realities for non-profit oriented museums, therefore, it is closely related to our case study, representing a non-profit, state-funded cultural organisation. For the purposes of this paper, Rentschler's model is adapted in order to explain the potential of international audiences' development. The following categories would serve as a point of reference: audience diversification, access and participation, diversity, social responsibility, and added value. Taking the specific location, institutional and operational characteristics of our case study, attracting the international audience segment can be achieved in several ways described below. 


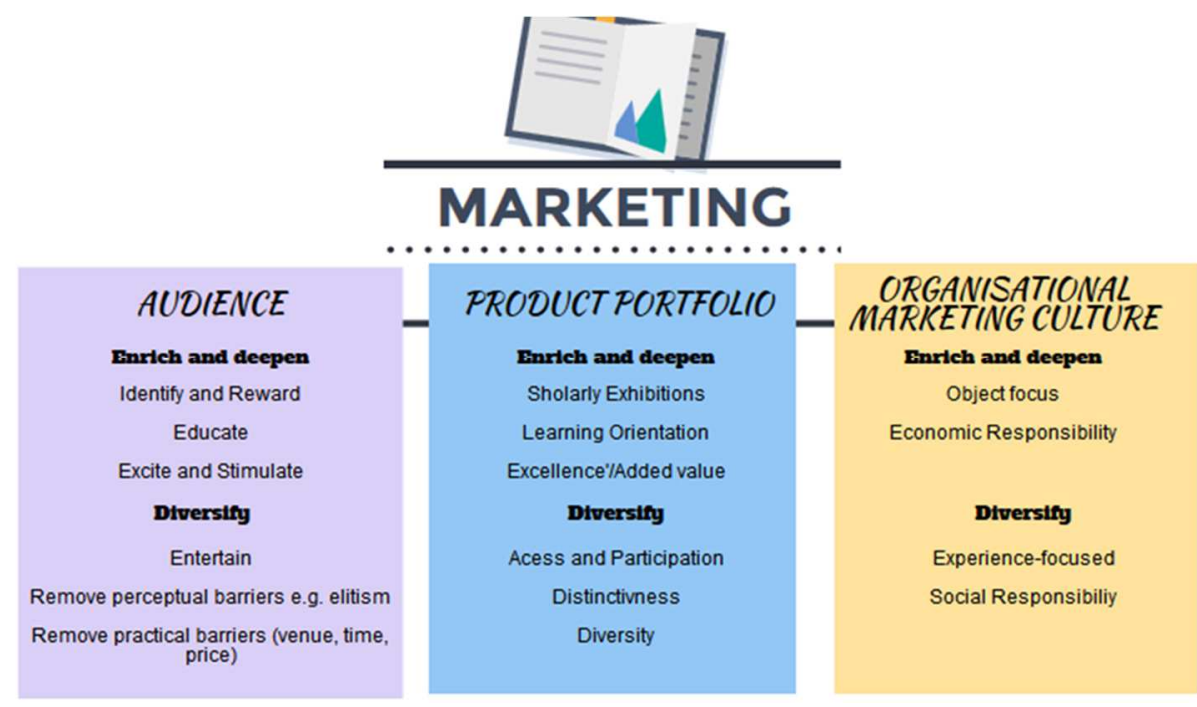

Figure 4. Renthschler's Tripartite audience, product and organisational marketing model Source: (Renthschler, 2004).

\section{Engagement With the Established Non-Nationals' Communities Networks}

For example, the Erasmus programme alone provides an excellent opportunity for international movie nights and meeting points for these audiences that are highly unexploited. In fact, Slovenia is among the top 10 countries for the number of hosted Erasmus students. Therefore, possible cooperation with organisations such as ESN and Erasmus Orientation Teams in different faculties (Faculty of Social Sciences, Faculty of Economy and others), can be extremely useful in order to organise such events, and to popularise the regular programme of Kinodvor. In the past, Kinodvor introduced collaboration with ISIC (International student identity card), and consequently a discount for cinema tickets. However, this collaboration is not exploited today. A better alternative may be collaboration with ESN - Erasmus Social Network cards, as majority of Erasmus students possess it. In order to develop a closer approach with the foreigners, another excellent opportunity for Kinodvor is provided by the Erasmus + programme; it could provide Erasmus traineeship for a EU student in a relevant discipline that can contribute a lot to the field, and will not cost the institution anything.

The international audience in total could extremely benefit from the Cinema's effort to integrate it into the Slovene culture, where classic Slovene movies could be shown exclusively with English subtitles and a following discussion can be of extreme importance not only to get to know the Slovene culture, but also for their own gathering and creation of relationships, in which Kindovor can become an irreplaceable part also in the future. Especially, if there is no possibility to translate the available marketing materials, such as brochures, monthly programmes and so on into English for financial reasons, having a channel of communication through organisations that are in direct contact with foreigners (Embassies, cultural institutes, student organisations, intercultural friendship associations, etc.) could help in passing on the message. Initiatives, that have started and received boost in 2015 , have proven as a valuable practice. 


\section{Digitalisation and Language}

In the digital age, the idea of the passive audience is largely redundant, if not completely invalidated. Contemporary audiences shape, influence, engage with or interact, and guide the practices and processes. Social media networks have popularised the Friend-Of-AFriend (FOAF) phenomenon and made viral effects on the norm for catchy memes - there are completely new ways of inheriting and cultivating audiences. An organisation's audience is not a homogeneous whole but rather a fragmented, loosely-coupled network that exists at a multiple, sometimes contradictory level, a part of which is the international audience cluster.

As the Generation $Y$, which goes to the cinema most frequently, without a connection to nationality, has grown up in the digital area and their communication and relationship building starts predominantly online, it is logical that online social networks are an excellent tool for Kinodvor to develop in this direction and reach the young people.

Digitalisation of communication and the Internet itself is not only a technology, but a totally new form of culture and communication, where the users' demands for cultural activities are changing. Today's users demand that art and culture must involve dialogue, they must be participatory, and that people can take part and interact (Mandel, 2015). Social communication technology provides a new type of consumer called 'the cultural participant' (Kolb, 2013). Therefore, social networks provide a platform that allows consumers to move beyond just attending the events, but to be actively engaged and provide their opinion - to involve consumers, and create a deeper relationship with the organisation. Marketing should not be focused merely on filling seats, but it should aim at creating relationships, associations and direct engagement with the public, and for young people the starting point of this relationship is online.

Here, the English language is of extreme importance due to its elevated status of an 'international language' that attracts expatriates' communities. Kinodvor has an English version of website, discussions with film creators are also held in English and an interesting event - to be held in 2016 - is the live streaming of International Film Festival Rotterdam screenings. In addition, Kinodvor's social media networks provide information in English during Open Air cinema summer events. All these aspects are of a great importance for the potential development of a future internationalisation strategy.

Also, the potential of rating websites such as TripAdvisor should not be ignored. Positive rating and feedback there guarantees an international inflow of young people who are in search for alternative and unique experiences that are typical for the place they visit and are appreciated by the locals, as a positive international image is a sign of unquestioned quality. Therefore, the interaction with foreigners is not only beneficial for the local community, but also attracts it. Kinodvor is on the Trip Advisor platform since quite recently, therefore, its profile provides scarce information, however, its presentation at the Visit Ljubljana tourist page is highly appealing to international communities, as it is described as: "A cinema for film connoisseurs showing high quality films for the more demanding cinema goer, with a special emphasis on European film" (Visit Ljubljana). Therefore, its potential for platforms such as Trip advisor and advertisement among the international audience should not be underexploited. 


\section{Re-Shaping the Urban Space, Complementing the Existing Services and Adding a Specific Advantage to the Location}

Kinodvor's strategy is predominantly oriented at the local community. However, this concentration in the dynamic consumer times cannot last if the local community does not experience personal self-actualisation and development, not only personally, but also in the institution with which it identifies. The expatriates' community represents an incentive of the meeting point, enhancing ideas and the film culture development at a level that currently does not exist in Ljubljana. In fact, as stated in interviews with the customers belonging to the non-nationals' community segment, Kinodvor is the only place in Slovenia that can develop such a potential on a daily basis due to its international programme and films that touch social issues of the global importance. Therefore, this positioning and intense everyday programme represents a competitive advantage in comparison with film festivals, seen as the major events where such thought exchange occurs. For these reasons, Kinodvor has established fruitful cooperation with the biggest international film festivals in Ljubljana (Liffe and Animateka), providing its hall for festival screenings and thus it has increased its social incentive contribution immensely.

Re-shaping the urban space is a part of this strategy that can bring many incentives not only for the institutions present in this area, but for the development of the whole district. A bit further from the centre, the Art Cinema is situated near Metelkova, the peak of alternative culture in Ljubljana, which resembles a Copenhagen's mini version of Christiania, combined with a hostel, being awarded for the best hostel on Trip advisor a few years ago - Hostel Celica ${ }^{1}$, a direct provider for travellers searching for alternative experiences. In a high contrast, right next to it, there is a newly built museum complex consisting of two Modern Art Museums, the Slovene ethnographic museum and a new part of the Slovene national museum. However, there is no platform which unites these four cultural institutions, and therefore it does not have an image of a common cultural place. In addition, the Metelkova square provides space for the open-air cinema and concerts. However, the different events and exhibitions occur separately and do not represent a common strategy.

The creation of a 'cultural experience triangle' formed by Kinodvor-Metelkova-Museum Quarter has the potential of district development and can help build this image of something unusual, out of the mainstream, that is so attractive for young Ljubljana and Slovenia residents who seek an unrepeatable experience.

\section{DISCUSSION AND CONCLUSIONS}

The paper examines an early internationalisation strategy of an enterprise in a creative industry and explores the option of internationalisation at home (before or even without foreign entry) by using the non-nationals and expatriates' community as a separate market segment. The literature on the international marketing segmentation lacks research regarding the non-national segments within countries. According to the available macro statistics and the case study evidence, this segment is increasingly relevant, especially in

\footnotetext{
${ }^{1}$ Former prison turned into a hostel, providing a unique experience for its guests. Its advertisement consists of 'Spend a night behind the bars'.
} 
terms of the European market development which promotes the free movement of people, capital and goods. Further research and development of marketing activities for this group (as well as more detailed segmentation of the non-nationals and expatriates' community within urban areas) would enable firms to exploit their existing international competitive advantages already on the home market. As entering a new foreign market is resource-intensive, such an alternative can be helpful for expanding companies from emerging markets and the markets that went through a transition to the liberal economy process, such as the Eastern European countries. Such a strategy is disruptive innovation and may not only reveal an international expansion potential, but also benefit from the home market environment in a various way that this paper explores, such as the non-nationals integration, the economic integration, the market openness, and the sustainable business development. The expatriates' community segment represents a new market to be targeted and explored, at home, but it also represents a specific consumer niche that needs to be further explored, followed and targeted in other countries.

The case study showed an underexploited potential of this segment, even when the product is clearly cross-national and its further development and expansion would greatly benefit with such segmentation within the marketing strategy. The advantages of this strategy are not only to target new audiences/customers but also to improve the strategic marketing development. The analysis of consumers proved the existence of the expatriates' community segment, although it has not been recognised in the CEO's perception and the initial firm's strategy.

Tackling an expatriates' community at home/on the domestic market is seen as an opportunity for starting internationalisation that has been overlooked not only in the CEE and in creative industries, but also in other industries and in other European cities where the expatriates' community is growing. The case study presents some proposals for targeting it.

The explorative research that helped to create this case study drew attention to the weaknesses of the existing market segmentation on the European markets and rapid changes in consumer segmentation in Europe, especially in the case of creative and culture industries. It illustrates a mismatch of priorities and the existing marketing segmentation and the need for further segmentation and research.

The case of Kinodvor may serve as incentive for future research; not only for developing improved and more sophisticated market segmentation, but also targeting the nonnationals and expatiates more successfully, and to analyse all (still) overlooked effects (for firm-specific advantages, industry- and location-specific advantages and the cultural diplomacy development) where internationalisation at home (on the home market) goes beyond the provision of an added value predominantly for the local community, which is an enterprise's initial target.

As this area has been poorly explored before, the research faces several limitations. There is a lack of strong empirical data on the subject, as such data is hard to collect since the segment faces both the long-term and the short-term mobility. This segment is flexible and changeable, therefore, marketing research on the responsiveness and further segmentation needs to be renewed regularly. This calls for the development of appropriate tools that would help recognise the potential. On the one hand, it presents a challenge due to the unstable market, on the other hand it shows the potential of reaching a growing 
market that crosses borders. Another limitation is that the strategy to start internationalisation at home via the expatriates' community is applicable only to certain urban locations (metropolises, capitals, cities with big population, popular destinations). The adoption of such a strategy may also meet strictly practical issues, such as language barriers, cultural misinterpretations and differences. However, the essence of those limitations shows that they can be overcome by means of further research and exploration of the topic. Next, the case study offers a challenge to build a strong conceptual model of internationalisation at home and integrate it into the existing internationalisation process model.

The presented strategy is relevant for enterprise organisational learning, the dynamics of internationalisation and performance. Implications of the idea to use the non-nationals and expatriates as a separate segment are not only relevant for European enterprises that may start internationalisation at home, but also for non-European enterprises finding the European community outside Europe or when entering European cities or city strategies themselves.

\section{REFERENCES}

Andersen, O. (1993). On the internationalisation process of firms: a critical analysis. Journal of International Business Studies, 24(2), 209-231.

Agarwal, M. K. (2003). Developing Global Segments and Forecasting Market Shares: A Simultaneous Approach Using Survey Data. Journal of International Marketing, 11(4), 56-80.

Beatty, S. E., Homer, P. M., \& Kahle, L. R. (1988). Problems With VALS in International Marketing Research: an Example From an Application of the Empirical Mirror Technique. Advances in Consumer Research, 15, 375-380.

Bell, J., Crick, D., \& Young, S. (2004). Small firm internationalization and business strategy: an exploratory study of 'knowledge intensive' and 'traditional' manufacturing firms in the UK. International Small Business Journal, 22(1), 23-56.

Cernat, L. (2006). Europeanization, Varieties of Capitalism and Economic Performance in Central and Eastern Europe, New York: Palgrave Macmillan.

Cook, A., \& Glass, C. (2015). Do Minority Leaders Affect Corporate Practice? Analyzing the Effect of Leadership Composition on Governance and Product Development. Strategic Organization, 13(2), 117-140.

Coviello, N.E., \& Munro, H.J. (1995). Network relationships and the internationalization process of small software firms. International Business Review, 6(4), 361-386.

Coviello, N.E., \& Martin, K.A. M. (1999). Internationalization of service SMEs: an integrated perspective from the engineering consulting sector. Journal of International Marketing, 7(4), 42-66.

Cravens, D.V., \& Woodruff, R.B. (1986). Marketing. Addison-Wesley Publishing Company.

Cui, G., \& Q. Liu. (2001). Emerging Market Segments in a Transitional Economy: A Study of Urban Consumers in China. Journal of International Marketing, 9(1), 84-106.

Dikova, D., Jaklič, A., Burger, A., \& Kunčič, A. (2016). What is beneficial for first-time SME-exporters from a transition economy: A diversified or a focused export-strategy? Journal of World Business, 51(2), 185-199. doi:10.1016/j.jwb.2015.05.001

Dunning, J. H. (1988). The Eclectic Paradigm of International Production: A Restatement and Some Possible Extensions. Journal of International Business Studies, 19(1), 1-31.

European Commission. (2014). Erasmus Facts, Figures \& Trends. Retrieved on July 10, 2015 from http://ec.europa.eu/ education/library/statistics/ay-12-13/facts-figures_en.pdf 
Eurostat. (2014a). Residence Permits Statistics. Retrieved on July 3, 2015 from http://ec.europa.eu/eurostat/statistics-explained/index.php/Residence_permits_statistics

Eurostat. (2014b). Migration and Migrant Population Statistics. Retrieved on July 3, 2015 from http://ec.europa.eu/eurostat/statistics-explained/index.php/Migration_and_migrant_population_statistics

Fillis, I. (2001). Small firm internationalisation: an investigative survey and future research directions. Management Decision, 39(9), 767-783.

Goethe-Institute \& Leuphana University. (2015). Human Factors International Quadrant. MOOC "Managing the Arts: Marketing for Cultural Organizations". Produced by Bilderfest factual entertainment.

Hassan, S. S., \& Katsanis, L. P. (1991). Identification of Global Consumer Segments. Journal of International Consumer Marketing, 3(2), 11-28.

Hofstede, T. F., Wedel, M., \& Steenkamp, J. E. M. (2002). Identifying Spatial Segments in International Markets. Marketing Science, 21(2), 160-177.

Hofstede, T.F., Steenkamp, J. E. M., \& Wedel, M. (1999). International Market Segmentation Based on Consumer-Product Relations. Journal of Marketing Research, 36(1), 1-17.

Hurmerinta, L., \& Nummela, N. (2011). Mixed-method case studies in international business research. In Piekkari \& Welch (Eds.), Rethinking the Case Study in International Business and Management Reserch. Cheltenham: Edward Elgar.

Inkei, P. (2007). Funding culture in Europe: public and private partnerships. Le recontee in Seville, 811 March, advanced online publication. Retrieved on July 16, 2015 from http://www.budobs.org/other-projects/sponsorship-and-taxes/231-funding-culture-in-europe-public-andprivate partnerships.html

Johanson, J., \& Vahlne, J.-E. (1977). The internationalization process of the firm: a model of knowledge development and increasing foreign market commitments. Journal of International Business Studies, 8(1), 23-32.

Johanson, J., \& Vahlne, J.-E. (1990). The mechanism of internationalisation. International Marketing Review, 7(4), 11-24.

Johanson, J., \& Vahlne, J.-E. (2009). The Uppsala internationalization process model revisited: from liability of foreignness to liability of outsidership. Journal of International Business Studies, 40, 1411-1431.

Johanson, J., \& Wiedersheim-Paul, F. (1975). The internationalization of the firm: four Swedish cases. Journal of Management Studies, 12(3), 305-322.

Kale, S. H., \& Sudharshan, D. (1987). A Strategic Approach to International Segmentation. International Marketing Review, 4(2), 60-70.

Kinodvor. (2011). Strategija Javnega Zavoda Kinodvor 2011-2015. Retrieved on July 3, 2015 from http://www.kinodvor.org/media/strategija_jz.kinodvor.2011-2015.pdf

Kreutzer, R.T. (1988), Marketing-Mix Standardization: An Integrated Approach in Global Marketing. European Journal of Marketing, 22(10), 19-30.

Lawson, R., \& Todd S. (2002). Consumer Lifestyles: A Social Stratification Perspective. Marketing Theory, 2(3), 295-307.

Lee, H., Kelley, D., Lee, J., \& Lee, S. (2012). SME survival: the impact of internationalization, technology resources, and alliances. Journal of Small Business Management, 50(1), 1-19.

Leonidou, L. C., \& Katsikeas, C. S. (1996). The export development process: an integrative review of empirical models. Journal of International Business Studies, 27(3), 517-551. 
Madsen, T., \& Servais, P. (1997). The internationalization of born globals: an evolutionary process? International Business Review, 6(6), 561-583.

Maister, P. (2015). A learning curve: how foreign students can provide an FDI boost. fDi Magazine, 12/8/2015. fDi Intelligence. The Financial Times.

Mandel, B. (2015). Arts Marketing and Audience Development. MOOC Managing the Arts: Marketing for Cultural Organizations. Goethe Institut e.V. \& Leuphana University. Produced by Bilderfest factual entertainment.

Mayoral, L., \& Alvarez, S. (2014). Internationalization From "Internationalization At Home": A Case Of Study In Unicen-Argentina. Global Conference on Business \& Finance Proceedings, 9(2), 17351743.

Mercado, S., Wellford, R., \& Prescott, K. (2001). European Business. Forth Edition. Essex, England: Prentice Hall Financial Times. Pearson Education Limited.

Ministrstvo za zunanje zadeve Republike Slovenije (2014). Izdana dovoljenja za prebivanje $v$ letu 2014. Retrieved on June 26, 2015 from http://www.mnz.gov.si/si/mnz_za_vas/tujci_v_sloveniji/

Ministrstvo za zunanje zadeve Republike Slovenije (2014). Veljavna dovoljenja za prebivanje $v$ letu 2014. Retrieved on June 26, 2015 from http://www.mnz.gov.si/si/mnz_za_vas/tujci_v_sloveniji/statistika/

Nairn, A., \& Berthon, P. (2003). Creating the Customer: The Influence of Advertising on Consumer Market Segments: Evidence and Ethics. Journal of Business Ethics, 42(1), 83-99.

Oviatt, B. M., \& McDougall, P. P. (1994). Toward a theory of international new ventures. Journal of International Business Studies, 25(1), 45-64.

Rentschlr, R. (2004). Museum Marketing: Understanding Different Types of Audiences. In F. Kerrigan, P. Fraser, \& M. Ozbilgin (Eds.), Arts Marketing (pp.139-158). Oxford: Elsevier.

Sierra, M. L. (2013). Becoming Global Without Leaving Home: Internationalization at Home, A Case Study of San Jorge, a Spanish Private University. University of Minnesota: ProQuest Dissertations Publishing.

SNG Opera and Ballet Ljubljana. Official Facebook page. Retrieved on June 26, 2015 from https://www.facebook.com/SNGOperalnBalet?fref=ts

Steenkamp, B. E. M., \& Baumgartner, H. (1998). Assessing Measurement Invariance in Cross-National Consumer Research. Journal of Consumer Research, 25(1), 78-107.

Svetličič, M., Jaklič, A., \& Burger, A. (2007). Internationalization of small and medium-size enterprises from selected central European economies. Eastern European Economics, 45(4), 36-65.

Williams, C. (1997). Consumer Services and Economic Development. Routledge.

Westhead, P., Wright, M., \& Ucbasaran, D. (2001). The internationalization of new and small firms: a resource-based view. Journal of Business Venturing, 16(4), 333-358.

Wright, M., Westhead, P., \& Ucbasaran, D. (2007). Internationalization of small and medium-sized enterprises (SMEs) and international entrepreneurship: a critique and policy implications. $R e-$ gional Studies, 41(7), 1013-1029.

Yankelovich, D., \& David, M. (2006). Rediscovering Market Segmentation. Harvard Business Review, 1-11.

Yavas, U., Verhage B. J., \& Green, R. T. (1992), Global consumer segmentation versus local market orientation: empirical findings. Management International Review, 32(3), 265-73. 
Yukiko, I. (2015). Realizing Internationalization At Home through English-Medium Courses at a Japanese University: Strategies to Maximize Student Learning. Higher Learning Research Communications, 5(1), 11-28.

\section{Authors}

The contribution share of authors is equal and amounted to $50 \%$ each of them.

\section{Andreja Jaklič}

Andreja Jaklič, professor of International Economics and a research fellow at the Centre of International Relations, University of Ljubljana, has earned her experience from several academic and applied international research projects related to internationalisation, export, FDI, MNEs, and their effects on competitiveness, growth, productivity and innovation activity. Her teaching courses involve: International Business, International Economic Relations, EU in the Global Economy and Research Methods.

\section{Paraskevi Karageorgu}

Paraskevi Karageorgu holds a Bachelor's degree in the European studies and is a master student of Cultural Studies at the Faculty of Social Sciences, University of Ljubljana, Slovenia. Her research area involves: European cultural policy, international marketing and creative industries. She has earned her experience via several different traineeships (including EXPO Milano and Embassy of the Republic of Bulgaria in Slovenia) and has volunteered twice in the Guest Management Department at Liffe film festival.

\section{Correspondence to:}

Prof. Andreja Jaklič,Ph.D.

Center of International Relations

Faculty of Social Sciences, University of Ljubljana

Kardeljeva pl. 5, 1000 Ljubljana, Slovenia

andreja.jaklic@fdv.uni-lj.si

\section{Acknowledgements and Financial Disclosure}

We wish to express our sincere gratitude to Kinodvor for excellent cooperation and providing us an opportunity to explore their organisation from many different perspectives.

\section{Copyright and License}

This article is published under the terms of the Creative Commons Attribution - NonCommercial - NoDerivs (CC BY-NC-ND 3.0) License http://creativecommons.org/licenses/by-nc-nd/3.0/ 